\title{
Tonsillectomy and breast cancer risk in the Western New York Diet Study
}

\author{
Theodore M. Brasky • Matthew R. Bonner • \\ Joan Dorn · James R. Marhsall · John E. Vena • \\ John R. Brasure · Jo L. Freudenheim
}

Received: 30 July 2008/Accepted: 10 October 2008/Published online: 26 October 2008

(C) The Author(s) 2008. This article is published with open access at Springerlink.com

\begin{abstract}
Objectives Exposures during early life may affect risk of breast cancer. History of tonsillectomy has recently been associated with risk of several cancers, including cancer of the breast.

Methods We conducted a population-based case-control study of women living in Western New York from 1986 to 1991. Cases had incident, primary, pathologically confirmed breast cancer and were recruited through all major hospitals in the region $(n=740)$. Population-based controls $(n=810)$ were randomly sampled from among drivers' license holders from Department of Motor Vehicles records $(<65$ yrs $)$ and from Health Care Finance Administration records ( $\geq 65$ yrs). Participants were interviewed with regard to diet, anthropometrics, demographics, medical, and reproductive history. Unconditional logistic regression models stratified by menopausal status were used to estimate multivariate odds ratios (OR) and $95 \%$ confidence intervals $(95 \% \mathrm{CI})$.

Results A history of tonsillectomy was associated with increased breast cancer risk among premenopausal (OR
\end{abstract}

T. M. Brasky $(\varangle) \cdot$ M. R. Bonner · J. Dorn ·

J. R. Brasure · J. L. Freudenheim

Department of Social and Preventive Medicine, School of Public

Health and Health Professions, University at Buffalo, Farber

Hall, Rm. 270, Buffalo, NY 14214, USA

e-mail: tmbrasky@buffalo.edu

J. R. Marhsall

Department of Cancer Prevention and Population Sciences,

Roswell Park Cancer Institute, Buffalo, NY, USA

J. E. Vena

Department of Epidemiology and Biostatistics, University

of Georgia, Athens, GA, USA
1.50, 95\% CI: $1.08-2.08)$ but not postmenopausal women (OR 1.05, 95\% CI: 0.79-1.38).

Conclusions Our findings add to accumulating data implicating tonsillectomy in risk of cancer. Tonsillectomy may be an indicator for conditions of chronic inflammation and/or reduced efficiency of immune function. Our study also provides additional evidence that early life exposures may affect premenopausal breast cancer risk.

Keywords Tonsillectomy - Breast cancer . Epidemiology · Case-control · Inflammation

\section{Introduction}

Many exposures during early life and childhood are believed to affect breast cancer risk [1-6]. While such exposures as age at menarche and at first birth have long been known as risk factors for breast cancer, other exposures including birthweight, pre-eclampsia during pregnancy, gestational age, twin status, and perinatal exposures including maternal age, birth order, and being breastfed may also affect risk $[1,3]$. There has been little research done regarding exposures during childhood, though there is evidence that growth during childhood may be associated with risk [4].

Tonsillectomy, a procedure that historically has been performed primarily on children, has been examined in relation to risk of several cancers. There is evidence that history of tonsillectomy is associated with increased risk of prostate cancer [7], leukemia [8, 9], and lymphoma [10]. In a study of breast cancer, Yasui et al. found an association of tonsillectomy after age 15 with risk [11]. For all of these cancers, if tonsillectomy is indeed etiologically related to cancer, it is not clear whether it is removal of the tonsils which affects risk or whether tonsillectomy is a proxy for 
another etiologic agent. For example, tonsillectomy during childhood and early adulthood may be a marker for clinical and sub-clinical infection and inflammation during childhood [12-14]. Surgical indications and standard practices have changed throughout the past century, making it more difficult to connect tonsillectomy to underlying conditions.

Evidence that inflammation increases the risk of cancer including breast cancer is accumulating [15]. Inflammation is characterized by tissue damage and regeneration, increased proliferation and vascularization. Inflammatory processes may increase free radical damage, activate oncogenes, and promote angiogenesis [16]. Anti-inflammatory drugs including nonsteroidal anti-inflammatory drugs (NSAIDs) may protect against tumorigenesis at several sites including breast cancer [17, 18]. We report here on a case-control study of breast cancer in which we examined the association of history of tonsillectomy with risk of breast cancer.

\section{Materials and methods}

\section{Subject selection}

The Western New York Diet Study was a population-based case-control study in Erie and Niagara counties. The study has been described in detail [19, 20]. Briefly, between 1986 and 1991, incident, primary, pathologically confirmed breast cancer cases were recruited through pathology records of all major hospitals in Erie and Niagara counties. After the patient was identified, her physician was contacted for permission to interview. If permission was granted, we obtained written informed consent from the patient. We interviewed $66 \%(n=301)$ of eligible premenopausal cases and 54\% $(n=439)$ of eligible postmenopausal cases. The study was approved by the institutional review board of the University at Buffalo and of all the cooperating hospitals.

Population-based controls $(n=810)$ were randomly sampled from among drivers' license holders from Department of Motor Vehicles records ( $<65 \mathrm{yrs})$ and from Health Care Finance Administration records ( $\geq 65$ yrs). We interviewed $62 \%(n=316)$ of eligible premenopausal controls and $44 \%(n=494)$ of eligible postmenopausal controls.

\section{Data collection}

The interview focused on dietary history, but data were also collected regarding anthropometrics, demographics, smoking, medical, and reproductive history. Included in the medical history was a question regarding whether the participant had ever had a tonsillectomy. Trained interviewers conducted in-person interviews in participants' homes; interviewers were blinded to case control status and study hypotheses. Interviews were limited to women who were able to speak English and were well enough to be interviewed.

\section{Statistical analysis}

We stratified all analyses by menopausal status. Women were considered postmenopausal if they were $\geq 50 \mathrm{yrs}$ of age and had ceased menstruation. We additionally classified women as postmenopausal if they were $<50$ yrs of age and did not have functioning ovaries (i.e., if they had experienced natural menopause, bilateral oopherectomy, or irradiation to the ovaries). The study was limited to Caucasian women.

We used $t$-tests and $\chi^{2}$ tests of independence to gauge the statistical significance of the association, respectively, of continuous and categorical variables to exposure and disease. Unconditional logistic regression was used to estimate multivariate-adjusted odds ratios (OR) and 95\% confidence intervals $(95 \% \mathrm{CI})$. All reported $p$-values are two-tailed. We adjusted multivariate analyses for known risk factors for breast cancer including age (continuous), years of education (continuous), family history of breast cancer (yes/no), history of benign breast disease (yes/no), body mass index (BMI; $\mathrm{kg} / \mathrm{m}^{2}$ ) 2 years prior to interview (continuous), age at menarche (continuous), and parity (yes/no). We additionally adjusted for age at menopause (continuous) and ever postmenopausal hormone use (yes/ no) for the analysis of risk of postmenopausal breast cancer. Allergy (e.g., self-reported asthma, food/medicine allergies) and atopy (e.g., contact dermatitis, hives) had negligible effect in multivariate models and were not included in final multivariate models. To probe whether secular changes in tonsillectomy affected breast cancer risk, we further examined the association by birth decades. The effect of nondifferential measurement error in selfreported tonsillectomy status was evaluated using sensitivity analysis outlined by Greenland [21].

\section{Results}

Selected characteristics of study participants, stratified by tonsillectomy, menopausal status and breast cancer status, are presented in Table 1. Among premenopausal cases and controls, age, years of education, body mass index, and history of benign breast disease were similar in those who had a tonsillectomy versus those who had not. Premenopausal controls who had a tonsillectomy were more likely to have a family history of breast cancer than controls that 
Table 1 Descriptive characteristics of Western New York Diet Study participants, stratified by menopausal status

\begin{tabular}{|c|c|c|c|c|c|c|}
\hline & \multicolumn{3}{|l|}{$\begin{array}{l}\text { Cases } \\
n=300\end{array}$} & \multicolumn{3}{|l|}{$\begin{array}{l}\text { Controls } \\
n=314\end{array}$} \\
\hline & $\begin{array}{l}\text { Tonsillectomy } \\
n=169\end{array}$ & $\begin{array}{l}\text { No tonsillectomy } \\
n=131\end{array}$ & & $\begin{array}{l}\text { Tonsillectomy } \\
n=141\end{array}$ & $\begin{array}{l}\text { No tonsillectomy } \\
n=173\end{array}$ & \\
\hline & Mean (SD) & Mean (SD) & $p$-Value & Mean (SD) & Mean (SD) & $p$-Value \\
\hline \multicolumn{7}{|l|}{ Premenopausal women } \\
\hline Age & $45.75(3.77)$ & $45.84(4.04)$ & 0.84 & $46.36(3.53)$ & $45.92(3.51)$ & 0.28 \\
\hline Years of education & $13.81(2.76)$ & $13.79(2.81)$ & 0.97 & $13.99(2.71)$ & $14.15(2.66)$ & 0.61 \\
\hline Body mass index & $24.54(5.12)$ & $25.85(6.31)$ & 0.06 & $25.74(5.05)$ & $25.76(5.38)$ & 0.98 \\
\hline Age at menarche & $12.48(1.48)$ & $12.62(1.75)$ & 0.47 & $12.76(1.75)$ & $12.79(1.70)$ & 0.87 \\
\hline \multirow[t]{2}{*}{ Age at first pregnancy ${ }^{\mathrm{a}}$} & $23.60(4.68)$ & $23.63(5.18)$ & 0.97 & $22.45(4.01)$ & $22.42(3.92)$ & 0.95 \\
\hline & $n(\%)$ & $n(\%)$ & & $n(\%)$ & $n(\%)$ & \\
\hline Family history of breast cancer & & & 0.62 & & & 0.02 \\
\hline No & $149(88.17)$ & $113(86.26)$ & & $126(89.36)$ & $166(95.95)$ & \\
\hline Yes & $20(11.83)$ & $18(13.74)$ & & $15(10.64)$ & $7(4.05)$ & \\
\hline History of benign breast disease & & & 0.28 & & & 0.52 \\
\hline No & $87(51.79)$ & $76(58.02)$ & & $89(63.57)$ & $116(67.05)$ & \\
\hline Yes & $81(48.21)$ & $55(41.98)$ & & $51(36.43)$ & $57(32.95)$ & \\
\hline Consume alcohol & & & 0.95 & & & 0.20 \\
\hline Never & $8(4.73)$ & $6(4.58)$ & & $7(4.96)$ & $4(2.31)$ & \\
\hline \multirow[t]{4}{*}{ Ever } & $161(95.27)$ & $125(95.42)$ & & $134(95.04)$ & $169(97.69)$ & \\
\hline & \multicolumn{3}{|l|}{$\begin{array}{l}\text { Cases } \\
n=436\end{array}$} & \multicolumn{3}{|l|}{$\begin{array}{l}\text { Controls } \\
n=487\end{array}$} \\
\hline & $\begin{array}{l}\text { Tonsillectomy } \\
n=220\end{array}$ & $\begin{array}{l}\text { No tonsillectomy } \\
n=216\end{array}$ & & $\begin{array}{l}\text { Tonsillectomy } \\
n=239\end{array}$ & $\begin{array}{l}\text { No tonsillectomy } \\
n=248\end{array}$ & \\
\hline & Mean (SD) & Mean (SD) & $p$-Value & Mean (SD) & Mean (SD) & $p$-Value \\
\hline \multicolumn{7}{|l|}{ Postmenopausal women } \\
\hline Age & $61.98(7.32)$ & $63.70(7.80)$ & 0.02 & $63.03(7.66)$ & $64.05(7.74)$ & 0.15 \\
\hline Years of education & $12.96(2.93)$ & $11.81(2.60)$ & $<0.01$ & $12.50(2.52)$ & $11.85(2.62)$ & $<0.01$ \\
\hline Body mass index & $25.86(5.10)$ & $27.05(5.84)$ & 0.02 & $25.35(5.08)$ & $25.88(5.32)$ & 0.27 \\
\hline Age at menarche & $12.65(1.49)$ & $12.98(1.60)$ & 0.03 & $12.89(1.68)$ & $12.84(1.46)$ & 0.73 \\
\hline Age at first pregnancy ${ }^{\mathrm{a}}$ & $24.55(4.64)$ & $24.41(4.95)$ & 0.79 & $23.95(4.38)$ & $23.15(4.68)$ & 0.07 \\
\hline \multirow[t]{2}{*}{ Age at menopause } & $46.61(6.76)$ & $47.67(5.56)$ & 0.08 & $45.90(6.45)$ & $46.94(6.41)$ & 0.08 \\
\hline & $n(\%)$ & $n(\%)$ & & $n(\%)$ & $n(\%)$ & \\
\hline Family history of breast cancer & & & 0.96 & & & 0.97 \\
\hline No & $184(83.64)$ & $181(83.80)$ & & $219(91.53)$ & $227(91.53)$ & \\
\hline Yes & $36(16.36)$ & $35(16.20)$ & & $20(8.37)$ & $21(8.47)$ & \\
\hline History of benign breast disease & & & 0.13 & & & 0.75 \\
\hline No & $157(71.36)$ & 167 (77.67) & & $192(80.67)$ & $202(81.78)$ & \\
\hline Yes & $63(28.64)$ & $48(22.33)$ & & $46(19.33)$ & $45(18.22)$ & \\
\hline Hormone replacement therapy & & & 0.03 & & & 0.02 \\
\hline Never & $145(60.42)$ & $174(70.16)$ & & $144(60.25)$ & $174(70.16)$ & \\
\hline Ever & $95(39.58)$ & $74(29.84)$ & & $95(39.75)$ & $74(29.84)$ & \\
\hline Consume alcohol & & & 0.54 & & & 0.96 \\
\hline Never & $21(9.55)$ & $17(7.87)$ & & $19(7.95)$ & $20(8.06)$ & \\
\hline Ever & $199(90.45)$ & 199 (92.13) & & $220(92.05)$ & 228 (91.94) & \\
\hline
\end{tabular}

a Among parous women 
did not have a tonsillectomy (Table 1). Among postmenopausal cases and controls, those who had a tonsillectomy were significantly younger, more educated, and more likely to have used hormone replacement therapy than those who had not. Postmenopausal cases who had a tonsillectomy had a significantly lower body mass index than those who had not had a tonsillectomy. No difference was observed for body mass index among postmenopausal controls. Family history of breast cancer did not vary by tonsillectomy status among postmenopausal cases or controls (Table 1).

Among premenopausal women, $56 \%$ of cases and $45 \%$ of controls reported having had a tonsillectomy; among postmenopausal women, case and control exposures to tonsillectomy were similar (50 and 49\%, respectively) (Table 2). We observed a significant positive association of breast cancer with history of tonsillectomy, which persisted after multivariate adjustment, among premenopausal (OR 1.50, 95\% CI: $1.08-2.08$ ) but not among postmenopausal women (OR 1.05, 95\% CI: 0.79-1.38) (Table 2).

When the data were analyzed by decade of birth, consistent with our findings of an association with premenopausal disease, there was some indication that risk was greatest for the youngest women (Table 3). We observed a modest inverse association of tonsillectomy with risk of breast cancer for those born in 1900-1920 (OR 0.77 , 95\% CI: 0.49-1.21), slightly elevated risks of breast cancer for those born in 1921-1930 and 1931-1940 (OR 1.26, 95\% CI: $0.84-1.89$; OR 1.27, 95\% CI: $0.84-1.91$, respectively), and a significantly elevated association of tonsillectomy on breast cancer risk in women born in the most recent birth cohort, 1941-1950 (OR 1.72, 95\% CI: $1.17-2.53)(p$-trend $=0.02)$.

\section{Discussion}

In this study of women in Western New York, we found that pre- but not postmenopausal women who had tonsillectomies were at increased risk of breast cancer. There was a trend observed by birth cohort, with the strongest association observed in the youngest study participants.

There is very little previous work addressing this question. Using data from a population-based case-control study of postmenopausal breast cancer in Washington State, Yasui et al. found that women who had a tonsillectomy after age 15 were at $68 \%$ increased risk of breast cancer, compared to women who had never had a tonsillectomy (OR 1.68, 95\% CI: 1.09-2.60); similarly, they also found evidence that risk was increased among women who had a tonsillectomy after menarche as compared to women who had never had their tonsils removed (OR 1.47, 95\% CI: 0.98-2.20) [11]. No association was observed in women whose tonsillectomy was performed prior to menarche [11]. We did not have information regarding the age at which tonsillectomy was performed. In a case-control study of women 30-80 yrs, Lubin et al. observed an increased risk of breast cancer diagnosed after $65 \mathrm{yrs}$ with prior tonsillectomy (OR 2.3, 95\% CI: 1.3-3.9) [22]. No increase in risk was observed in women diagnosed between 30 and 44 yrs, and a slight increase in risk was observed in women diagnosed between 45 and 54 yrs (OR 1.2) [22]. The results observed by Yasui et al. and Lubin et al. differ with our own findings of an association of tonsillectomy with pre- but not postmenopausal breast cancer.

Few studies have investigated the association of tonsillectomy with cancer at other sites. History of this procedure has been found to be associated with increased risk of Hodgkin's disease, leukemia, and prostate cancer, though results have been mixed [7, 9, 10, 23-25]. Liaw et al. recently observed a $40 \%$ increased risk of Hodgkin's disease among a cohort of Swedish patients who had a tonsillectomy in comparison to the general population (SIR 1.4) [10]. Vineis et al. observed in a case-control study a nonsignificant twofold increased risk of lymphoblastic leukemia with tonsillectomy at $>10$ yrs; no association was found with ever having a tonsillectomy [9]. Tonsillectomy was associated with a twofold risk of prostate cancer in a prospective cohort of Harvard University students [7]. In a more recent hospital-based case-control study in Serbia, there was no association with cancer of the prostate [25].

If there is, in fact, an etiological connection of tonsillectomy and cancer risk, there are several mechanisms which might account for it. Tonsillectomy may be a proxy measure for increased infection during childhood. Clinical and subclinical infections could invoke a strong inflammatory response. There is evidence that inflammation may increase risk $[15,16]$. In particular for breast cancer risk, prostanoid synthesis resulting from COX-2 activation is correlated with estrogen synthesis and breast cell proliferation in vitro [26]. Alternatively, as the tonsils function to produce lymphocytes, it is thought that they are involved in immunologic defenses. Their removal may impair immune surveillance $[7,9,10,27]$. The rationale for the surgery would certainly affect the likelihood of these hypothesized mechanisms. The differences we observed across birth decades may reflect changes in practice. While the tonsillectomies of the study participants were likely in response to childhood illness, there were changes in the acceptable indication for these practices over time, and changes in surgical method [12-14]. We do not have data for these study participants on the age at which they had their tonsils removed, the method by which the tonsils were removed, nor the surgical indication. One possible explanation for the difference in association that we observed for younger women may relate to secular changes in indications for this 
Table 2 Odds ratios and 95\% confidence intervals of tonsillectomy and breast cancer, stratified by menopausal status

\begin{tabular}{|c|c|c|c|c|c|}
\hline & $\begin{array}{l}\text { Cases } \\
n(\%)\end{array}$ & $\begin{array}{l}\text { Controls } \\
n(\%)\end{array}$ & $\begin{array}{l}\text { Crude OR } \\
(95 \% \mathrm{CI})^{\mathrm{a}}\end{array}$ & $\begin{array}{l}\text { Age and education adjusted } \\
\text { OR }(95 \% \mathrm{CI})\end{array}$ & $\begin{array}{l}\text { Multivariate adjusted } \\
\text { OR }(95 \% \mathrm{CI})\end{array}$ \\
\hline \multicolumn{6}{|c|}{ Premenopausal } \\
\hline \multicolumn{6}{|c|}{ Tonsillectomy } \\
\hline No & $131(43.67)$ & $173(55.10)$ & 1.00 ref. & 1.00 ref. & 1.00 ref. \\
\hline Yes & $169(56.33)$ & $141(44.90)$ & $1.59(1.16-2.19)$ & $1.60(1.16-2.20)$ & $1.50(1.08-2.08)$ \\
\hline \multicolumn{6}{|c|}{ Postmenopausal } \\
\hline \multicolumn{6}{|c|}{ Tonsillectomy } \\
\hline No & $216(49.54)$ & $248(50.92)$ & 1.00 ref. & 1.00 ref. & 1.00 ref. \\
\hline Yes & $220(50.46)$ & $239(49.08)$ & $1.06(0.82-1.37)$ & $1.03(0.79-1.34)$ & $1.05(0.79-1.38)$ \\
\hline
\end{tabular}

${ }^{\text {a }}$ OR, odds ratio; $95 \%$ CI, $95 \%$ confidence interval

b Adjusted for adjusted for age, education, family history of breast cancer, benign breast disease, BMI, age at menarche, parity, age at menopause (postmenopausal women), and hormone replacement therapy (postmenopausal women)

Table 3 Relationship of tonsillectomy with breast cancer by birth decade

\begin{tabular}{lll}
\hline Birth decade & Cases/controls & OR $(95 \% \mathrm{CI})^{\mathrm{a}, \mathrm{b}}$ \\
\hline $1900-1920$ & $144 / 196$ & $0.77(0.49-1.21)$ \\
$1921-1930$ & $195 / 201$ & $1.26(0.84-1.89)$ \\
$1931-1940$ & $377 / 372$ & $1.27(0.84-1.91)$ \\
$1941-1950$ & $428 / 426$ & $1.72(1.17-2.53)$ \\
& & $p$-trend $=0.02$ \\
\hline
\end{tabular}

Referent group is no history of tonsillectomy within each decade of birth

${ }^{\text {a }}$ OR, odds ratio; $95 \% \mathrm{CI}, 95 \%$ confidence interval

$\mathrm{b}$ Adjusted for age and education

surgery. Another explanation may be that recurrent tonsillitis, a once-common surgical indication, may represent a more intense inflammatory state in those women whose childhood occurred after the introduction of antibiotics. Alternatively, younger women might have better recall of the surgery, but there is accumulating evidence that early life exposures are more related to pre- than to postmenopausal breast cancer [5, 6, 28].

Our study has a number of pertinent limitations related to the selection of subjects and collection of information. We were able to recruit $58 \%$ of eligible cases and $50 \%$ of eligible controls. With such response rates, the distribution of tonsillectomies in the case or control group could misrepresent the distributions in the source populations. It is possible that the resulting selection bias could by chance produce spurious results. Tonsillectomy during childhood has been positively correlated with social-economic status (SES) [29]. However, we did not observe meaningful differences in SES between cases and controls. As surgery was likely during childhood, SES at the time of surgery may be an important consideration. We did not collect SES information for participants' parents and we were unable to assess it as a potential confounder.

In addition, participant tonsillectomy status may have been misclassified. A reliability study which compared self-reported tonsillectomy to a physical exam showed $76 \%$ sensitivity [30]. There is little reason to believe that such misclassification would be differential (i.e., recall bias) as cases and controls were not aware of tonsillectomy as a study hypothesis; but it is possible. We observed no evidence of blanket recall bias with cases over-reporting all exposures. If premenopausal cases were more likely to over-report tonsillectomy, it may result in an inflated point estimate. Nondifferential misclassification of tonsillectomy status would attenuate our results toward the null. We performed a sensitivity analysis of our results assuming $76 \%$ sensitivity and $85 \%$ specificity of self-reported tonsillectomy among both cases and controls. Under this assumption, the true OR for premenopausal women could be as high as 2.15. The true OR for postmenopausal women would not change substantially (1.09) at this level of misclassification.

In conclusion, we observed a significantly increased risk of breast cancer among pre- but not postmenopausal women with a history of tonsillectomy. This finding adds to evidence that exposures in childhood may impact the risk of breast cancer, particularly among premenopausal women. Further research investigating the role of tonsillectomy in breast carcinogenesis is needed to confirm these results and to elucidate potential mechanisms. In particular, studies with data regarding tonsillectomy status, age and menarche status at tonsillectomy, and indication for tonsillectomy are warranted.

Acknowledgments This work was supported in part by grant CA11535 from the National Cancer Institute, National Institutes of Health, and grant PDT-434 from the American Cancer Society. 
Open Access This article is distributed under the terms of the Creative Commons Attribution Noncommercial License which permits any noncommercial use, distribution, and reproduction in any medium, provided the original author(s) and source are credited.

\section{References}

1. Forman MR, Cantwell MM, Ronckers C, Zhang Y (2005) Through the looking glass at early-life exposures and breast cancer risk. Cancer Invest 23:609-624. doi:10.1080/07357 900500283093

2. Okasha M, McCarron P, Gunnell D, Smith GD (2003) Exposures in childhood, adolescence and early adulthood and breast cancer risk: a systematic review of the literature. Breast Cancer Res Treat 78:223-276. doi:10.1023/A:1022988918755

3. Potischman N, Troisi R (1999) In-utero and early life exposures in relation to risk of breast cancer. Cancer Causes Control 10:561-573. doi:10.1023/A:1008955110868

4. Ahlgren M, Melbye M, Wohlfahrt J, Sorensen TIA (2004) Growth patterns and the risk of breast cancer in women [see comment]. N Engl J Med 351:1619-1626. doi:10.1056/NEJMoa 040576

5. Barba M, McCann SE, Nie J et al (2006) Perinatal exposures and breast cancer risk in the Western New York Exposures and Breast Cancer (WEB) Study. Cancer Causes Control 17:395-401. doi: 10.1007/s10552-005-0481-5

6. Nie J, Beyea J, Bonner MR et al (2007) Exposure to traffic emissions throughout life and risk of breast cancer: the Western New York Exposures and Breast Cancer (WEB) study. Cancer Causes Control 18:947-955. doi:10.1007/s10552-007-9036-2

7. Whittemore AS, Paffenbarger RS Jr, Anderson K, Lee JE (1985) Early precursors of site-specific cancers in college men and women. J Natl Cancer Inst 74:43-51

8. Schuz J, Kaletsch U, Meinert R, Kaatsch P, Michaelis J (1999) Association of childhood leukaemia with factors related to the immune system. Br J Cancer 80:585-590. doi:10.1038/sj.bjc. 6690395

9. Vineis P, Miligi L, Crosignani P et al (2003) Delayed infection, late tonsillectomy or adenoidectomy and adult leukaemia: a casecontrol study. Br J Cancer 88:47-49. doi:10.1038/sj.bjc.6600689

10. Liaw KL, Adami J, Gridley G, Nyren O, Linet MS (1997) Risk of Hodgkin's disease subsequent to tonsillectomy: a population-based cohort study in Sweden. Int J Cancer 72:711-713. doi:10.1002/ (SICI)1097-0215(19970904)72:5<711::AID-IJC1>3.0.CO;2-V

11. Yasui Y, Potter JD, Stanford JL et al (2001) Breast cancer risk and "delayed" primary Epstein-Barr virus infection. Cancer Epidemiol Biomarkers Prev 10:9-16

12. Darrow DH, Siemens C (2002) Indications for tonsillectomy and adenoidectomy. Laryngoscope 112:6-10. doi:10.1097/00005537200208001-00004
13. Rosenfeld RM, Green RP (1990) Tonsillectomy and adenoidectomy: changing trends. Ann Otol Rhinol Laryngol 99:187-191

14. Younis RT, Lazar RH (2002) History and current practice of tonsillectomy. Laryngoscope 112:3-5. doi:10.1097/00005537200208001-00003

15. Aggarwal BB, Shishodia S, Sandur SK, Pandey MK, Sethi G (2006) Inflammation and cancer: how hot is the link? Biochem Pharmacol 72:1605-1621. doi:10.1016/j.bcp.2006.06.029

16. Baniyash M (2006) Chronic inflammation, immunosuppression and cancer: new insights and outlook. Semin Cancer Biol 16:80 88. doi:10.1016/j.semcancer.2005.12.002

17. Harris RE, Beebe-Donk J, Doss H, Burr Doss D (2005) Aspirin, ibuprofen, and other non-steroidal anti-inflammatory drugs in cancer prevention: a critical review of non-selective COX-2 blockade. Oncol Rep 13:559-583

18. Khuder SA, Mutgi AB (2001) Breast cancer and NSAID use: a meta-analysis. Br J Cancer 84:1188-1192. doi:10.1054/bjoc. 2000.1709

19. Freudenheim JL, Marshall JR, Vena JE et al (1996) Premenopausal breast cancer risk and intake of vegetables, fruits, and related nutrients. J Natl Cancer Inst 88:340-348. doi:10.1093/ jnci/88.6.340

20. Graham S, Hellmann R, Marshall J et al (1991) Nutritional epidemiology of postmenopausal breast cancer in Western New York. Am J Epidemiol 134:552-566

21. Greenland S (1996) Basic methods for sensitivity analysis of biases. Int J Epidemiol 25:1107-1116. doi:10.1093/ije/25.6.1107-a

22. Lubin JH, Burns PE, Blot WJ et al (1982) Risk factors for breast cancer in women in northern Alberta, Canada, as related to age at diagnosis. J Natl Cancer Inst 68:211-217

23. Bonelli L, Vitale V, Bistolfi F, Landucci M, Bruzzi P (1990) Hodgkin's disease in adults: association with social factors and age at tonsillectomy. A case-control study. Int J Cancer 45:423427. doi:10.1002/ijc. 2910450307

24. Serraino D, Franceschi S, Talamini R et al (1991) Socioeconomic indicators, infectious diseases and Hodgkin's disease. Int J Cancer 47:352-357. doi:10.1002/ijc.2910470307

25. Ilic M, Vlajinac H, Marinkovi J (1996) Case-control study of risk factors for prostate cancer. Br J Cancer 74:1682-1686

26. Brueggemeier RW, Diaz-Cruz ES, Li P-K, Sugimoto Y, Lin YC, Shapiro CL (2005) Translational studies on aromatase, cyclooxygenases, and enzyme inhibitors in breast cancer. J Steroid Biochem Mol Biol 95:129-136. doi:10.1016/j.jsbmb.2005.04.013

27. Scadding GK (1990) Immunology of the tonsil: a review. J R Soc Med 83:104-107

28. Gunnell D, Okasha M, Smith GD, Oliver SE, Sandhu J, Holly JM (2001) Height, leg length, and cancer risk: a systematic review. Epidemiol Rev 23:313-342

29. Fry J (1957) Are all "T's and A's" really necessary? Br Med J 1:124-129

30. Prior AJ, Drake-Lee AB (1991) Auditing the reliability of recall of patients for minor surgical procedures. Clin Otolaryngol 16:373-375. doi:10.1111/j.1365-2273.1991.tb00952.x 